\title{
A cross-sectional examination of psychological distress, positive mental health and their predictors in medical students in their clinical clerkships
}

Inge van Dijk ${ }^{1,2^{*}}$ (D) Peter L. B. J. Lucassen ${ }^{2}$, Chris van Weel ${ }^{2,3}$ and Anne E. M. Speckens ${ }^{1}$

\begin{abstract}
Background: Medical students can experience the transition from theory to clinical clerkships as stressful. Scientific literature on the mental health of clinical clerkship students is scarce and mental health is usually defined as absence of psychological distress without assessing psychological, emotional and social wellbeing, together called 'positive mental health'. This cross-sectional study examines the prevalence of psychological distress and positive mental health and explores possible predictors in a Dutch sample of clinical clerkship students.

Methods: Fourth-year medical students in their first year of clinical clerkships were invited to complete an online questionnaire assessing demographics, psychological distress (Brief Symptom Inventory), positive mental health (Mental Health Continuum- SF), dysfunctional cognitions (Irrational Beliefs Inventory) and dispositional mindfulness skills (Five Facet Mindfulness Questionnaire). Multiple linear regression analysis was used to explore relationships between psychological distress, positive mental health (dependent variables) and demographics, dysfunctional cognitions and dispositional mindfulness skills (predictors).

Results: Of 454 eligible students, 406 (89\%) completed the assessment of whom 21\% scored in the clinical range of psychological distress and $41 \%$ reported a flourishing mental health. These proportions partially overlap each other. Female students reported a significantly higher mean level of psychological distress than males. In the regression analysis the strongest predictors of psychological distress were 'acting with awareness' (negative) and 'worrying' (positive). Strongest predictors of positive mental health were 'problem avoidance' (negative) and 'emotional irresponsibility' (negative).

Conclusions: The prevalence of psychopathology in our sample of Dutch clinical clerkship students is slightly higher than in the general population. Our results support conclusions of previous research that psychological distress and positive mental health are not two ends of one continuum but partially overlap. Although no conclusion on causality can be drawn, this study supports the idea that self-awareness and active, nonavoidant coping strategies are related to lower distress and higher positive mental health.
\end{abstract}

Keywords: Clinical clerkships, Medical students, Multiple linear regression, Positive mental health, Psychological distress

\footnotetext{
* Correspondence: inge.vandijk@radboudumc.nl

${ }^{1}$ Department of Psychiatry, Radboud University Medical Center, Nijmegen, the Netherlands

${ }^{2}$ Department of Primary and Community Care, Radboud University Medical

Center, Nijmegen, the Netherlands

Full list of author information is available at the end of the article
}

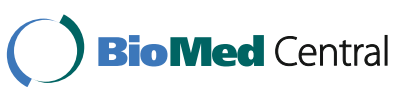

(c) The Author(s). 2017 Open Access This article is distributed under the terms of the Creative Commons Attribution 4.0 International License (http://creativecommons.org/licenses/by/4.0/), which permits unrestricted use, distribution, and reproduction in any medium, provided you give appropriate credit to the original author(s) and the source, provide a link to the Creative Commons license, and indicate if changes were made. The Creative Commons Public Domain Dedication waiver (http://creativecommons.org/publicdomain/zero/1.0/) applies to the data made available in this article, unless otherwise stated. 


\section{Background}

Clinical clerkships are a valuable part of medical education in which students can lay the foundation for their professional development. Unfortunately, the transition from theory to practice can result in problems related to professional socialization, high workload and heightened levels of psychological distress [1-5]. Although this transition is known to be stressful, scientific literature on the mental health of clinical clerkships students is scarce compared to literature on pre-clinical students and response rates are modest [6-9]. Prevalence rates of clinical clerkship students scoring above the cut-off for psychopathology vary from 27 to $48 \%[6,8,10,11]$. Mental health problems during clerkships are a predictor of postgraduate mental health problems in need of treatment $[12,13]$. Although there are no data available on the relationship between student psychopathology and their actual performance during clinical clerkships, we do know that higher distress, burnout, and depression in residents are associated with more self-perceived errors [14-17].

Mental health as 'presence or absence of disease' is only one approach to the well-being of medical students. In 2011, Huber et al. opened a discussion with their paper 'How should we define health', by stating that we should move away from the static WHO definition of health as 'a state of complete physical, mental and social well-being and not merely the absence of disease or infirmity' [18]. They suggest to use the more dynamic definition 'health is the ability to adapt and to self-manage', because this reflects the capacity to cope, maintain and restore one's integrity. In research on mental health, adopting this view could mean a shift from the emphasis on presence or absence of psychological distress to a broader definition in which also characteristics of psychological wellbeing and coping are used to determine a person's mental health.

Already for over a decade, Carol Ryff, professor of psychology at the University of Wisconsin, is studying psychological wellbeing of which she distinguishes six dimensions: self-acceptance, positive relations, autonomy, environmental mastery, purpose in life and personal growth [19]. Keyes and colleagues combined these dimensions of psychological wellbeing with dimensions of emotional wellbeing (e.g. being happy, interested in life and satisfied) and social wellbeing (e.g. feeling part of a community) which together he called 'positive mental health' or just 'mental health'. In this paper, we will use 'positive mental health' as term for psychological, emotional and social wellbeing while 'psychological distress' represents the experience of symptoms of distress such as sadness, sleeplessness or anxiety. Positive mental health and psychological distress both fall within the scope of the overarching concept 'mental health' (see Fig. 1).
Positive mental health and psychological distress are not two ends of a single continuum, but two related yet distinctive concepts, which are complementary to each other and show some overlap [20, 21]. The absence of psychological distress can contribute to a positive mental health but does not guarantee or equal positive mental health and vice versa. For example, a person with a mental disorder such as an obsessive-compulsive disorder can at the same time feel happy, experience a purpose in life and have positive relations, which are aspects of positive mental health. The combination of levels of positive mental health and psychological distress is a better predictor of psychosocial functioning of a person than one of these alone [20, 22]. A cross-sectional study of Keyes and colleagues among 5689 college students showed that higher levels of positive mental health were associated with less suicidal behaviour and academic impairment in students both with and without a current mental illness [23]. Specifically in medical students, the prevalence of suicidal ideation, serious thoughts of dropping out and the prevalence of unprofessional behaviours declined as positive mental health improved [24].

Examining predictors of psychological distress and positive mental health could heighten understanding of how not only quality of life of students but indirectly also quality of patient care could be influenced positively. Looking at what is known about the predictors of psychological distress in medical students; neuroticism, perfectionism, high reality weakness, low maternal care, high performance-based self-esteem, disengagement and type A personality were found to be positively correlated with depressive symptoms $[8,13,25]$. While selfactualization, self-awareness and a sense of fulfilment showed an inverse correlation with depression [25]. Predictors of positive mental health (as defined by Ryff) in medical students have not been studied yet.

\section{Current study}

With the current cross-sectional study we first aim to determine the prevalence of psychological distress and positive mental health in a sample of Dutch medical students in their clinical clerkships. Second, by means of regression analysis we will explore predictors of psychological distress and positive mental health from a number of demographic characteristics, dysfunctional cognitions, and dispositional mindfulness skills. We chose to explore the demographic characteristics gender, marital status, religion and nationality as in previous research in other target groups all of them were associated with levels of psychological distress and/or psychological wellbeing [26-35].

The dysfunctional cognitions we are interested in ('worrying', 'rigidity, 'need for approval, 'emotional irresponsibility' and 'problem avoidance') are based on 


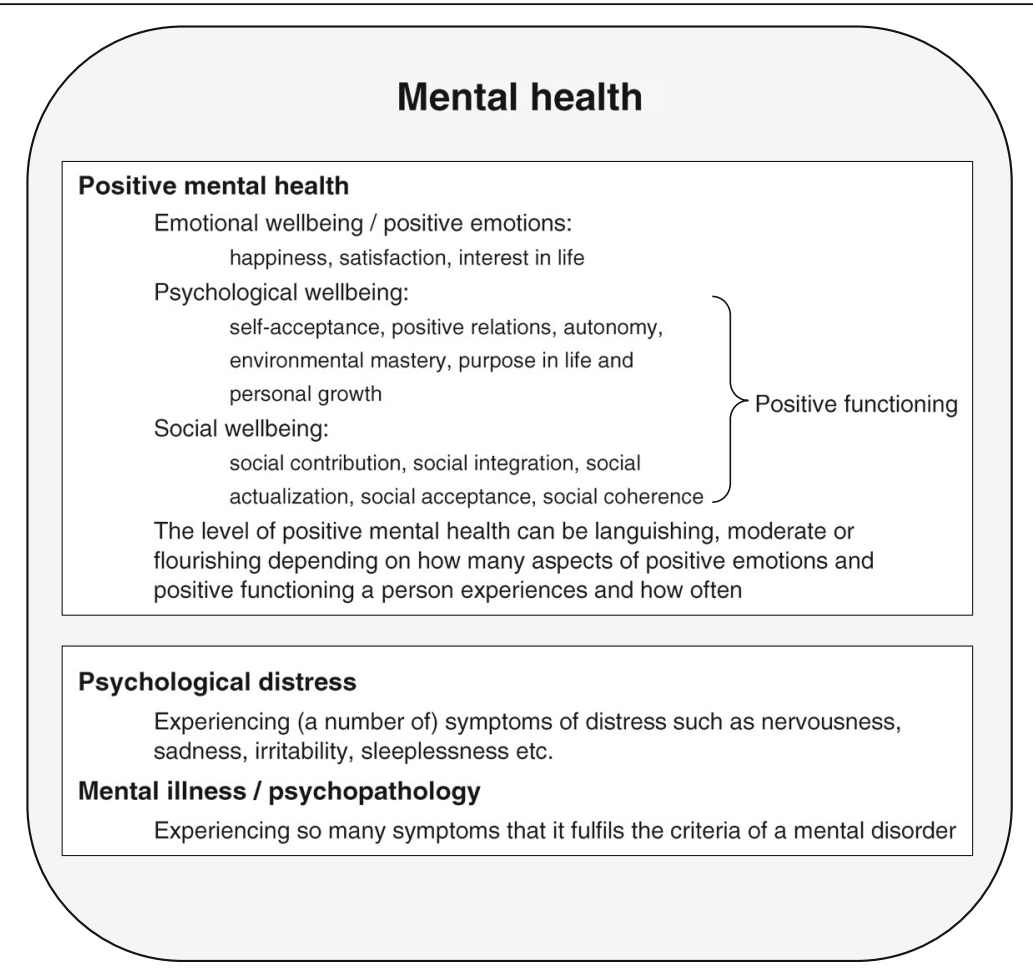

Fig. 1 Overview of terminology as used in the current paper

Ellis' theory on irrational cognitions people can have about themselves, for example, the idea that suffering and misfortune is beyond their influence (emotional irresponsibility) or that one needs other people's approval to be happy (need for approval). We hypothesize the dysfunctional cognition 'worrying' to be a strong predictor of psychological distress as worrying is highly correlated to neuroticism, a known risk factor for psychological distress in the general population as well as in medical students [12, 13, 36, 37]. We expect a less strong connection of worrying to positive mental health.

We are also interested in dispositional mindfulness; the natural ability to be aware of one's current thoughts, feelings and other experiences in a curious, non-judging way without being trained to do so. In other studies, higher levels of dispositional mindfulness were associated with lower levels of distress [38-41] and higher positive states of mind [42]. It also moderated the relationship between self-care and psychological distress and the relationship between self-control and psychological symptoms [40] and explained significant variance in psychological health [40].

\section{Methods}

\section{Setting}

The medical school curriculum of the Radboud University Medical Center in Nijmegen consists of a three-year pre-clinical Bachelor study in which students study medical theory followed by a three-year Master study consisting of clinical rotations in two- or threemonth periods alternated by a one-month period of reflection, study and preparation for the next clerkship.

\section{Subjects}

From February 2011 to August 2012 we invited all firstyear clinical clerkship students in the fifth month of their clerkships to complete an online survey, which was accessible at home with a personalized link. All participating students gave informed consent before completing the survey.

\section{Ethical considerations}

The study was embedded in two studies which were approved of by the medical ethical research committee Arnhem-Nijmegen.

\section{Outcome measures Psychological distress}

The Brief Symptom Inventory (BSI) is a 53-item questionnaire, measuring psychological symptoms of distress. It can be used in both clinical and non-clinical populations. It focusses on dimensions of somatization, cognitive problems, interpersonal sensitivity, depression, anxiety, hostility, phobic fear, paranoid thoughts and psychoticism [43]. A five-point Likert scale is used to score items from 'none-at-all' to 'extremely'. The mean 
score on all 53 items, which is called the global severity index' (range 0-4), is widely used in studies as a measure of overall psychological distress. A higher score implies a higher level of psychological distress. The Dutch BSI has been found to have a high reliability and high validity [44, 45]. A cut-off score of 0.58 or higher on the global severity index is proposed for screening on psychopathology [44].

\section{Positive mental health}

We used the 14-item Mental Health Continuum-Short Form (MHC-SF) as a measure of positive mental health, consisting of the three dimensions emotional, psychological and social wellbeing. Emotional wellbeing exists of three items assessing how often during the past month a person was feeling happy, interested in life and satisfied. Psychological wellbeing is measured by six items based on the model of Ryff assessing selfacceptance, positive relations, autonomy, environmental mastery, purpose in life and personal growth. Social wellbeing is assessed by five items asking about social contribution, social integration, social actualization, social acceptance and social coherence. Together the eleven items of social wellbeing and psychological wellbeing are called the items of positive functioning (see Fig. 1) [21]. All 14 items range from 'never' to 'daily' on a six-point Likert scale, total score range 0-70. A higher score indicates a higher level of positive mental health. The degree of positive mental health of a person can also be expressed in the categories 'flourishing,' 'moderate' and 'languishing' mental health. Experiencing 'every day' or 'almost every day' at least one of the three items of emotional wellbeing and at least six of the eleven items of positive functioning during the past month or 2 weeks is considered 'flourishing mental health'. 'Languishing mental health' is categorized in persons with a combination of low scores on at least one item of emotional well-being and on at least six items of positive functioning. All other combinations represent 'moderate mental health'. Studied in a representative sample of the Dutch population, internal reliability was high $(\alpha=0.89)$ and validity good for the Dutch total MHC-SF [21].

\section{Possible predictors}

\section{Demographic variables}

We assessed age, gender, relationship status and religious background.

\section{Dysfunctional cognitions}

We used the five subscales of the 50-item Irrational Beliefs Inventory to assess students' irrational cognitions, which are considered to be related to a person's vulnerability for developing psychopathology [46]. The IBI is derived from the Irrational Beliefs Test [47] and the Rational Behaviour Inventory [48] but with improved psychometric quality. The subscales are worrying, rigidity, need for approval, problem avoidance, and emotional irresponsibility. They are rated on a five-point Likert scale from 'strongly disagree' to 'strongly agree, total score range 50-250. A higher score indicates a higher level of dysfunctional cognitions. In a randomly selected Dutch university student sample validity and reliability $(\alpha=0.83-0.85)$ were satisfactory $[49,50]$.

\section{Mindfulness skills}

With the 39-item Five Facet Mindfulness Questionnaire (FFMQ) five domains of mindfulness skills are assessed: observing, describing, acting with awareness, nonjudging of inner experience and non-reactivity to inner experience [51]. Items are rated on a five-point Likerttype scale from 'never or very rarely true' to 'very often or always true', total score range 39-195. A higher score implying a higher level of mindfulness skills. The subscales of the Dutch FFMQ have been shown to have good internal consistency [52].

\section{Statistical analysis}

We collected all data by means of an online survey tool (Limesurvey) and exported them to IBM SPSS statistics 21.0 for analysis.

\section{Descriptive statistics}

We used descriptive statistics to assess all variables. We used independent sample t-tests to compare age and gender of all participating students and non-participants and to compare positive mental health scores of men and women. For the dependent variable psychological distress, we used a non-parametric test to compare scores across men and women, because of skewed data. Despite this, we reported mean instead of median scores, for the sake of comparability across literature and clarity in reporting cut-off scores to determine individual cases.

\section{Analyses}

In preparation of performing multiple linear regression analyses, we used Kolmogorov-Smirnov tests and visual inspection (Q-Q plots, histograms) to assess normality of all variables. Assumptions of linearity, heteroscedasticity, and independence of residuals were assessed by means of inspecting residual plots. We assessed correlations between each of the two dependent variables and the independent variables (demographic characteristics, dysfunctional cognitions, and mindfulness skills) using Pearson's correlation coefficient $(r)$ and Spearman's rho in case of non-normal distributions. Psychological distress and positive mental health were our primary outcome measures (dependent variables). We used the global severity index of the Brief Symptom Inventory as 
a measure of psychological distress and the total score of the Mental Health Continuum-SF as a measure of positive mental health. We performed multiple linear regression analyses to assess relationships between our dependent and independent variables. As students were grouped in classes at the time of inclusion, data was nested, therefore the intra-class correlation coefficient (ICC) was calculated for both dependent variables to assess if multilevel regression was necessary. In both dependent variables the ICC was redundant and therefore required no further multilevel analyses. Independent variables with significant correlations with the dependent variable were entered into the model simultaneously. Multicollinearity was assessed by means of correlation matrices, tolerance and Variance Inflation Factor (VIF) values. Durbin-Watson statistics were calculated to assess the dependence of variables. To investigate the unique relationship of psychological distress with the independent variables we corrected for positive mental health by entering it in the model. Also, to investigate the unique relationship of positive mental health with the independent variables, we entered psychological distress in the model. By means of backward elimination, variables with non-significant contributions to the model were removed. Both final models contained only the variables contributing significantly to the model. Squared semi-partial correlations were computed to determine the proportion of unique variance that each predictor contributed to the total explained variance of the model.

\section{Results}

\section{Demographic characteristics}

In total, $406(89 \%)$ of 467 eligible students completed the online assessment. Of the 61 students refusing to participate, 48 provided data on gender and age, revealing no significant differences between participants and non-participants.

Table 1 shows that the vast majority of the students was female (75\%) and in a relationship (58\%). The percentage of $3 \%$ students being of non-Dutch nationality is exactly equal to regional statistics reported by Statistics Netherlands. About half of the students considered themselves religious, mainly Catholic. Missing values analysis showed that $6 \%$ of the cases contained missing values and that $2.4 \%$ of data were missing.

\section{Prevalence of psychological distress and positive mental health}

Overall, $21 \%$ of the students reported a level of psychological distress above the cut-off score for psychopathology (Table 2). Female students reported a significantly higher mean level of psychological distress than male students. A flourishing mental health was reported by
Table 1 Characteristics of participating clinical clerkship students $(n=406)$

\begin{tabular}{|c|c|}
\hline \multicolumn{2}{|l|}{ Demographic characteristics } \\
\hline Age, median & 23.0 \\
\hline Female gender, $\mathrm{n}(\%)$ & $306(75.4)$ \\
\hline \multicolumn{2}{|l|}{ Marital status, n (\%) } \\
\hline Single & $170(41.9)$ \\
\hline In relationship, not married & $225(55.5)$ \\
\hline Married & $10(2.5)$ \\
\hline Divorced & $1(0.2)$ \\
\hline \multicolumn{2}{|l|}{ Nationality, n (\%) } \\
\hline Dutch & $388(95.6)$ \\
\hline German & $9(2.2)$ \\
\hline Other & $4(0.9)$ \\
\hline Missing & $5(1.2)$ \\
\hline \multicolumn{2}{|l|}{ Religion, n (\%) } \\
\hline Atheist & $196(48.3)$ \\
\hline Catholic & $120(49.6)$ \\
\hline Protestant & $24(5.9)$ \\
\hline Muslim & $11(2.7)$ \\
\hline Other & $49(12.1)$ \\
\hline Missing & $6(1.5)$ \\
\hline \multicolumn{2}{|l|}{ Personal characteristics } \\
\hline \multicolumn{2}{|l|}{ Dysfunctional cognitions, mean score (SD) } \\
\hline Worrying (range 12-60) & $33.5(7.6)$ \\
\hline Rigidity (range 14-70) & $36.0(5.8)$ \\
\hline Need for approval (range 7-35) & $23.5(4.3)$ \\
\hline Emotional irresponsibility (range 7-35) & $22.2(4.0)$ \\
\hline Problem avoidance (range 10-50) & $23.1(4.9)$ \\
\hline \multicolumn{2}{|l|}{ Mindfulness skills, mean score (SD) } \\
\hline Observing (range 8-40) & $21.6(5.6)$ \\
\hline Describing (range 8-40) & $28.0(5.9)$ \\
\hline Acting with awareness (range 8-40) & $29.7(5.6)$ \\
\hline Non-judging (range 8-40) & $30.9(6.0)$ \\
\hline
\end{tabular}

$37.5 \%$ of the female students, and $51 \%$ of the male students, a non-significant difference after correction for multiple testing. Table 3 shows that psychological distress and positive mental health are not two ends of one continuum but partially overlap. The majority of students with high levels of distress (77\%) report a moderate positive mental health and $18 \%$ of them reports a flourishing positive mental health.

Multiple linear regression model of psychological distress Correlations between psychological distress and the possible predictors are shown in Table 4 . The final model for predictors of psychological distress is shown in 
Table 2 Psychological distress and positive mental health in participating clinical clerkship students

\begin{tabular}{|c|c|c|c|c|}
\hline & Total & Women & Men & $p$ value $^{b}$ \\
\hline \multicolumn{5}{|l|}{ Psychological distress } \\
\hline Global severity index, M (SD) & $0.39(0.29)$ & $0.41(0.29)$ & $0.30(0.28)$ & $<0.001^{c}$ \\
\hline Above cut-offa, $\mathrm{n}(\%)$ & $86(21.2)$ & $72(23.6)$ & $14(14.0)$ & .05 \\
\hline \multicolumn{5}{|l|}{ Positive mental health } \\
\hline Total score, M (SD) & $45.7(10.3)$ & $45.3(10.1)$ & $46.8(10.8)$ & .21 \\
\hline \multicolumn{5}{|l|}{ Positive mental health, categories } \\
\hline Languishing, n (\%) & $5(1.3)$ & $4(1.4)$ & $1(1.0)$ & .07 \\
\hline Moderate, n (\%) & $225(57.8)$ & $179(61.1)$ & $46(47.9)$ & \\
\hline Flourishing, n (\%) & $159(40.9)$ & $110(37.5)$ & $49(51.0)$ & \\
\hline
\end{tabular}

${ }^{a}$ a cut-off score of 0.58 is advised in Dutch samples to screen for psychopathology

${ }^{b}$ In case of skewed/categorised data non-parametric Mann-Whitney $U$ tests and Chi-square tests were used

${ }^{c}$ remained significant after Bonferroni correction for multiple testing $0.05 / 4=$ alpha level 0.0125

Table 5. It contains the three significant predictors that remained after backward elimination of non-significant variables from the model. The mindfulness skill 'acting with awareness' was the strongest inversely correlated predictor for psychological distress, uniquely explaining $7.1 \%$ of total variance. The dysfunctional cognition 'worrying' uniquely explained $6.1 \%$ of the variance, making it the strongest positively correlating predictor. The mindfulness skill 'non-judging' made a smaller, but significant contribution uniquely explaining $2.6 \%$ of the variance. The final model explained $50 \%$ of the total variance in psychological distress.

Multiple linear regression model of positive mental health Table 4 shows correlations between positive mental health and its possible predictors. The final model for predictors of positive mental health is shown in Table 6 . It also contains three significant predictors after backward elimination and explains $21.9 \%$ of the variance in positive mental health. The dysfunctional cognition 'problem avoidance' is the strongest inversely correlated predictor explaining $3.1 \%$ of the variance, followed by 'emotional irresponsibility' explaining $1.6 \%$ of the variance and 'worrying' explaining $0.9 \%$ of the variance.

The highest Variance Inflation Factor score of our variables was 1.5 in the model of psychological distress and 1.6 in the model of positive mental health. In both

Table 3 Positive mental health in clinical clerkship students with low and high psychological distress

\begin{tabular}{|c|c|c|}
\hline & $\begin{array}{l}\text { Low distress }^{a} \\
(n=307)\end{array}$ & $\begin{array}{l}\text { High distress } \\
(n=82)\end{array}$ \\
\hline \multicolumn{3}{|l|}{ Positive mental health, categories } \\
\hline Languishing mental health, n (\%) & $1(0.3)$ & $4(4.9)$ \\
\hline Moderate mental health, n (\%) & $162(52.8)$ & $63(76.8)$ \\
\hline Flourishing mental health, n (\%) & $144(46.9)$ & $15(18.3)$ \\
\hline
\end{tabular}

models this value was well below 10 indicating that multicollinearity was not a problem.

\section{Discussion}

In this study, $21 \%$ of students scored above cut-off level for psychopathology and $41 \%$ reported a flourishing mental health The inversely related mindfulness skill 'acting with awareness' was the strongest predictor for psychological distress and for positive mental health the strongest predictor was the dysfunctional cognition 'problem avoidance', also inversely related.

Table 4 Correlations between psychological distress, positive mental health and possible predictors $(n=389)$

\begin{tabular}{lll}
\hline & $\mathrm{PD}^{\mathrm{a}}$ & $\mathrm{PMH}$ \\
\hline Demographic variables & $-.23^{* *}$ & .06 \\
Gender (f/m) & -.06 & -.03 \\
Age (yrs) & $-.12^{*}$ & .05 \\
Relationship (n/y) & -.01 & .07 \\
Religious (n/y) & .01 & -.03 \\
Nationality (Dutch/other) & & \\
Dysfunctional cognitions & $.59^{* *}$ & $-.35^{* *}$ \\
Worrying & .00 & -.02 \\
Rigidity & $.39^{* *}$ & $-.19^{* *}$ \\
Need for approval & .06 & $-.14^{* *}$ \\
Emotional irresponsibility & $.26^{* *}$ & $-.29^{* *}$ \\
Problem avoidance & & \\
Mindfulness skills & $.16^{* *}$ & -.03 \\
Observing & $-.23^{* *}$ & $.21^{* *}$ \\
Describing & $-.52^{* *}$ & $.32^{* *}$ \\
Acting w. awareness & $-.51^{* *}$ & $.29^{* *}$ \\
Non-judging & $-.19^{* *}$ & $.19^{* *}$ \\
Non-reacting & & \\
\hline
\end{tabular}

$P D$ Psychological distress, $P M H$ Positive mental health

$* P<.05 * * P<.01$

a spearman's rho 
Table 5 Multiple linear regression model of psychological distress

\begin{tabular}{lllll}
\hline & \multicolumn{4}{l}{ Psychological distress } \\
\cline { 2 - 6 } Predictors & Standardized $\beta$ & $\mathrm{t}$ & Unique variance (\%) & $P$ value \\
\hline Acting w. & -0.31 & -7.4 & 7.1 & $<.001$ \\
awareness & & & & $<.0$ \\
Worrying & 0.30 & 6.8 & 6.1 & $<.001$ \\
Non-judging & -0.20 & -4.5 & 2.6 & \\
Corrected for: & & & & $<.001$ \\
$\begin{array}{l}\text { Positive mental } \\
\text { health }\end{array}$ & -0.14 & -3.4 & 1.5 & \\
& Total model & & & $P$ \\
& $R^{2}$ & Adj. $R^{2}$ & $F$ & $<.001$ \\
\hline
\end{tabular}

\section{Prevalence of psychological distress and positive mental health}

The $21 \%$ of clinical clerkship students scoring above the cut-off for psychopathology is slightly lower than the $27 \%$ of Swedish students entering clinical training (Mini International Neuropsychiatric Interview) [8] and the $25 \%$ of Australian students in their internships (General Health Questionnaire-28) [11] and substantially lower than the $37 \%$ in Iranian clerkship students (General Health Questionnaire-28) [10].

It is even less than half the amount of the $48 \%$ as reported in the only other Dutch study by Gaspersz and colleagues, who screened for common mental disorders in a sample of pre-clinical and clinical students with combined response rate of $52 \%$. This finding is in line with the conclusion of Hope et al. in their systematic review on depression, anxiety and psychological distress outside North-America, that studies with higher quality and a response rate higher than $80 \%$, in general, find lower rates of psychological distress.

Table 6 Multiple linear regression model of positive mental health

\begin{tabular}{lllll}
\hline & \multicolumn{4}{l}{ Positive mental health } \\
\cline { 2 - 5 } Predictors & Standardized $\beta$ & $\mathrm{t}$ & Unique variance (\%) & $P$ value \\
\hline $\begin{array}{l}\text { Problem } \\
\text { avoidance }\end{array}$ & -0.19 & -3.9 & 3.1 & $<.001$ \\
$\begin{array}{l}\text { Emotional } \\
\text { Irresponsibility }\end{array}$ & -0.13 & -2.8 & 1.6 & $<.01$ \\
$\begin{array}{l}\text { Worrying } \\
\text { Corrected for: }\end{array}$ & -0.12 & -2.1 & 0.9 & .037 \\
$\begin{array}{l}\text { Psychological } \\
\text { distress }\end{array}$ & -0.27 & -4.8 & 4.7 & \\
& Total model & & & $<.001$ \\
& $R^{2}$ & Adj. $R^{2}$ & $F$ & \\
& 21.9 & 21.1 & 26.9 & $<.001$ \\
\hline
\end{tabular}

Regarding differences between countries; working environment and responsibilities of students during their clinical clerkships might vary. Also, the threshold that students experience to report symptoms of psychological distress could be influenced by cultural differences. Specifically for American students, one could hypothesize that the high study debt compared to other (European) countries might contribute to the difference in rates of psychopathology. However, scientific literature so far does not show a clear relationship between student level of debt and psychological distress [53] and between debt and positive mental health [24]. Debt was, however, significantly associated with suicidal ideation in the previous year, but not with future suicidal ideation [54].

The percentage of students reporting a flourishing mental health in our sample was twice as high as the percentage of students scoring above cut-off for psychopathology. Dyrbye et al. suggest a flourishing mental health can attenuate consequences of high levels of distress [24]. Students with a mental disorder but with flourishing positive mental health might be less at risk than those with languishing positive mental health. Investigating this further would give more information on which students might be in need of support.

\section{Predictors of psychological distress}

The only other study examining predictors of psychological distress specifically in clinical clerkship students is a longitudinal Swedish study which explored effects of personality traits and study environment on psychiatric morbidity. Only depressive symptoms at first year remained a significant predictor of psychiatric morbidity at third year when entered in a model with the other potential predictors workload, worries about future competence, financial worries, impulsivity, negative affectivity, performance based self-esteem and disengagement at first year [8]. The finding that external factors such as workload and financial worries did not significantly predict psychopathology was also reported in studies among medical students from different years: A 1-year prospective longitudinal study in medical students from all 6 years in two Dutch medical faculties showed that mental health problems were not significantly predicted by exogenous study factors such as study delay, study hours per week, study stressors or having a part-time job but by the personal factors 'worry about health' (risk factor) and 'excessive drinking behaviour' (protective factor) [55]. This is similar to the results of Bore and colleagues, [56] who examined 20 possible endogenous and exogenous predictors of psychological distress among 127 Australian medical students from year 1 to 5 . They found that not gender, demographics, hours studying, paid work or volunteer work were most important, but that emotional resilience was the 
strongest predictor of psychological distress. Emotional resilience could be described as being emotionally stable, calm and grounded as opposed to emotionally reactive (neurotic). This is in line with our findings that the endogenous factors acting with awareness (negative) and worrying (positive) are stronger predictors of psychological distress than demographic variables.

The only other study, besides ours, examining the relationship between dispositional mindfulness and psychological distress is that of Slonim and colleagues in Australian medical students from year 1 to 5. [38] Similar to our results, they also found the subscales 'acting with awareness' and 'non-judging' to be most strongly associated with lower levels of depression and anxiety. It is interesting that also in other target groups like for example men with advanced prostate cancer [57], fibromyalgia patients [58], and a community sample comprising of non-meditators and experienced meditators [59] of all FFMQ subscales 'acting with awareness' and 'non-judging' are strongest associated with lower psychological distress.

'Acting with awareness' refers to a person's ability to focus on present moment experiences. Possibly, a person with a high level of self-awareness is less bothered by ruminative thoughts and more responsive to his own needs, which could decrease psychological distress. It could also be the other way around; a person experiencing a high level of psychological distress might be unable to focus on the present moment experience, therefore being less self-aware.

\section{Predictors of positive mental health}

So far, no other studies have examined predictors of positive mental health in clinical clerkship students or other medical students. However, there are two Dutch studies in other target groups which have examined predictors of positive mental health. In a sample of 1161 Dutch participants from a representative internet panel between the ages of 18 and 88, agreeableness and extraversion were uniquely related to positive mental health whereas emotional instability was uniquely related to psychological distress. Agreeableness (being warm, empathic and friendly) and extraversion (being outgoing, social) are both aspects which are important in interpersonal relationships, an important aspect of positive mental health. The second Dutch study was a randomized controlled trial $(n=93)$ which showed that Acceptance and Commitment Therapy improved positive mental health of participants and that psychological flexibility during the intervention mediated the effects. That psychological flexibility, the ability to accept aversive internal experiences, is related to positive mental health seems similar to our finding that 'problem avoidance' and 'emotional irresponsibility' are its inversely related predictors. Coping with problems in an active way and maintaining an internal locus of control seem to improve positive mental health. Again this could also be the other way around; students with high positive mental health might be better able to approach problems in an active way and remain in control.

Above findings are in line with the definition of health as 'the ability to adapt and to self-manage'. An approaching coping style can be seen as a healthy way to adapt to a new situation and self-management relates to the locus of control of students. Clinical clerkships are eminently a period in which students are confronted with complex situations, insecurity, and suffering, which requires the ability to adapt and self-manage to remain a healthy professional. Furthermore, the fact that psychological distress and positive mental health share the predictor 'worrying', but also have a few separate predictors is supportive for the hypothesis that they are related, but distinct concepts and not two ends of the same continuum.

\section{Strengths and limitations}

Although it is also reported in other studies that the explained variance by personality traits is higher in psychopathology than in positive mental health [60], the fact that only $21 \%$ of variance in positive mental health was explained by our predictors compared to $50 \%$ of variance in psychological distress could mean that we did not manage to find the most important predictors of positive mental health yet. In light of the definition of Huber and colleagues it would be interesting to investigate the relationship between positive mental health and resilience, which is defined as 'positive adaptation despite experiences of significant adversity or trauma.' This might be more relevant to clinical clerkships than the dysfunctional cognitions that we used in our current study. Our study is cross-sectional in nature, therefore we cannot make any assumptions on causality. Also, we performed our study in one university medical centre, which could limit the generalizability of results. Strengths of our study are the high response rate (89\%) and medium-large sample size.

\section{Conclusion}

The prevalence of psychopathology in our sample of Dutch clinical clerkship students is slightly higher than in the general population. Although no conclusion on causality can be drawn, this study supports the idea that self-awareness and active, nonavoidant coping strategies are related to lower distress and higher positive mental health. Supporting the development of these skills might contribute to student wellbeing. The combination of levels of psychological distress and positive mental health might also be a better indicator of which students are in need of support than levels of psychological distress alone. More longitudinal research needs to be done to investigate these hypotheses. 


\section{Abbreviations}

BSI: Brief symptom inventory; FFMQ: Five facet mindfulness questionnaire; IBI: Irrational beliefs inventory; IBM: International business machines; ICC: Intra-class correlation coefficient; MHC-SF: Mental health continuum-short form;

SPSS: Statistical package for the social sciences; VIF: Variance inflation factor; WHO: World Health Organization

\section{Acknowledgements}

The authors thank all students that participated for their time and effort.

\section{Funding}

This study was financed by the Department of Psychiatry and Department of Primary and Community Care of the Radboudumc and by a grant of the department of Evaluation, Quality and Development of Education of the Radboudumc. They were not involved in the design or conduction of the study or in the writing of the paper.

\section{Availability of data and materials}

The datasets used and analysed during the current study are available from the corresponding author on reasonable request.

\section{Authors' contributions}

IVD contributed to data-collection, performed the statistical analyses, drafted and revised the manuscript. PL contributed to analyses and interpretation of data and revised the manuscript. CvW contributed to interpretation of data and to revision of the manuscript. AS participated in the design, datacollection and coordination of the study and contributed to the revision of the manuscript. All authors have read and approved the final manuscript.

\section{Ethics approval and consent to participate}

The study was embedded in two studies which were approved of by the medical ethical research committee Arnhem-Nijmegen. Protocol registration nr. 2010/388 and ABR nr: NL33969.091.10. Students could only continue to the online questionnaires after giving written online informed consent.

\section{Consent for publication}

Not applicable.

\section{Competing interests}

The authors declare that they have no competing interests.

\section{Publisher's Note}

Springer Nature remains neutral with regard to jurisdictional claims in published maps and institutional affiliations.

\section{Author details}

'Department of Psychiatry, Radboud University Medical Center, Nijmegen, the Netherlands. ${ }^{2}$ Department of Primary and Community Care, Radboud University Medical Center, Nijmegen, the Netherlands. ${ }^{3}$ Department of Health Services Research and Policy, Australian National University, Canberra, Australia.

Received: 10 February 2017 Accepted: 2 November 2017

Published online: 17 November 2017

\section{References}

1. Helmers KF, Danoff D, Steinert Y, Leyton M, Young SN. Stress and depressed mood in medical students, law students, and graduate students at McGill University. Acad Med. 1997;72:708-14

2. Sen S, Kranzler HR, Krystal JH, Speller H, Chan G, Gelernter J, et al. A prospective cohort study investigating factors associated with depression during medical internship. Arch Gen Psychiatry. 2010;67:557-65.

3. Prince KJ, van de Wiel M, Scherpbier AJ, Cess PM, Boshuizen HP. A qualitative analysis of the transition from theory to practice in undergraduate training in a PBL-medical school. Adv Health Sci Educ. 2000; 5:105-16.

4. Prince KJAH, Boshuizen HPA, Van Der Vleuten CPM, Scherpbier AJJA Students' opinions about their preparation for clinical practice. Med Educ. 2005;39:704-12.
5. Compton MT, Carrera JM, Frank E. Stress and depressive symptoms/ Dysphoria among US medical students: results from a large, nationally representative survey. J Nerv Ment Dis. 2008;196:891-7.

6. Gaspersz R, Frings-Dresen MHW, Sluiter JK. Prevalence of common mental disorders among Dutch medical students and related use and need of mental health care: a cross-sectional study. Int J Adolesc Med Health. 2012; 24:169-72.

7. Assadi SM, Nakhaei MR, Najafi F, Fazel S. Mental health in three generations of Iranian medical students and doctors. Soc Psychiatry Psychiatr Epidemiol. 2007:42:57-60.

8. Dahlin ME, Runeson B. Burnout and psychiatric morbidity among medical students entering clinical training: a three year prospective questionnaire and interview-based study. BMC Med Educ. 2007:7:6.

9. Mosley TH Jr, Perrin SG, Neral SM, Dubbert PM, Grothues CA, Pinto BM. Stress, coping, and well-being among third-year medical students. Acad Med. 1994;69:765-7

10. Shariati M, Yunesian M, Vash JH. Mental health of medical students: a cross-sectional study in Tehran. Psychol Rep. 2007;100:346-54.

11. Willcock SM, Daly MG, Tennant CC, Allard BJ. Burnout and psychiatric morbidity in new medical graduates. Med J Aust. 2004;181:357-60.

12. Tyssen R, Vaglum P, Grønvold NT, Ekeberg O. Factors in medical school that predict postgraduate mental health problems in need of treatment. A nationwide and longitudinal study. Med Educ. 2001;35:110-20.

13. Støen Grotmol K, Gude T, Moum T, Vaglum P, Tyssen R. Risk factors at medical school for later severe depression: a 15-year longitudinal, nationwide study (NORDOC). J Affect Disord. 2013;146:106-11.

14. West CP, Tan AD, Habermann TM, Sloan JA, Shanafelt TD. Association of resident fatigue and distress with perceived medical errors. JAMA. 2009;302:1294.

15. West CP, Huschka MM, Novotny PJ, Sloan JA, Kolars JC, Habermann TM, et al. Association of perceived medical errors with resident distress and empathy: a prospective longitudinal study. JAMA. 2006;296:1071.

16. Prins JT, van der Heijden FMMA, Hoekstra-Weebers JEHM, Bakker AB, van de Wiel HBM, Jacobs B, et al. Burnout, engagement and resident physicians' self-reported errors. Psychol Health Med. 2009;14:654-66.

17. Fahrenkopf AM, Sectish TC, Barger LK, Sharek PJ, Lewin D, Chiang WW, et al. Rates of medication errors among depressed and burnt out residents: prospective cohort study. BMJ. 2008;336:488-91.

18. Huber M, Knottnerus JA, Green L, Horst HVD, Jadad AR, Kromhout D, et al. How should we define health? BMJ. 2011;343:d4163.

19. Ryff CD. Happiness is everything, or is it? Explorations on the meaning of psychological well-being. J Pers Soc Psychol. 1989;57:1069-81.

20. Keyes CLM. The mental health continuum: from languishing to flourishing in life. J Health Soc Behav. 2002;43:207-22.

21. Lamers SMA, Westerhof GJ, Bohlmeijer ET, ten Klooster PM, Keyes CLM. Evaluating the psychometric properties of the mental health continuum-short form (MHC-SF). J Clin Psychol. 2011;67:99-110.

22. Keyes CLM. Mental illness and/or mental health? Investigating axioms of the complete state model of health. J Consult Clin Psychol. 2005;73:539-48.

23. Keyes CLM, Eisenberg D, Perry GS, Dube SR, Kroenke K, Dhingra SS. The relationship of level of positive mental health with current mental disorders in predicting suicidal behavior and academic impairment in college students. J Am Coll Heal. 2012;60:126-33.

24. Dyrbye LN, Harper W, Moutier C, Durning SJ, Power DV, Massie FS, et al. A multi-institutional study exploring the impact of positive mental health on medical students' professionalism in an era of high burnout. Acad Med. 2012:87:1024-31.

25. Dyrbye LN, Thomas MR, Shanafelt TD. Systematic review of depression, anxiety, and other indicators of psychological distress among US and Canadian medical students. Acad Med. 2006;81:354-73.

26. Steel Z, Marnane C, Iranpour C, Chey T, Jackson JW, Patel V, et al. The global prevalence of common mental disorders: a systematic review and meta-analysis 1980-2013. Int J Epidemiol. 2014:43:476-93.

27. Seedat S, Scott K, Angermeyer MC, et al. Cross-national associations between gender and mental disorders in the world health organization world mental health surveys. Arch Gen Psychiatry. 2009;66:785-95.

28. Bijl RV, Ravelli A, van Zessen G. Prevalence of psychiatric disorder in the general population: results of the Netherlands mental health survey and incidence study (NEMESIS). Soc Psychiatry Psychiatr Epidemiol. 1998:33:587-95.

29. Takeuchi DT, Speechley KN. Ethnic differences in the marital status and psychological distress relationship. Soc Psychiatry Psychiatr Epidemiol. 1989; 24:288-94. 
30. Holt-Lunstad J, Birmingham W, Jones BQ. Is there something unique about marriage? The relative impact of marital status, relationship quality, and network social support on ambulatory blood pressure and mental health. Ann Behav Med. 2008:35:239-44.

31. Cotten SR. Marital status and mental health revisited: examining the importance of risk factors and resources. Fam Relat. 1999:48:225-33.

32. Bonelli RM, Koenig HG. Mental disorders, religion and spirituality 1990 to 2010: a systematic evidence-based review. J Relig Health. 2013;52:657-73.

33. Weber SR, Pargament Kl. The role of religion and spirituality in mental health. Curr Opin Psychiatry. 2014;27:358-63.

34. Bratter JL, Eschbach K. Race/ethnic differences in nonspecific psychological distress: evidence from the National Health Interview Survey*. Soc Sci Q. 2005:86:620-44

35. Levecque K, Lodewyckx I, Bracke P. Psychological distress, depression and generalised anxiety in Turkish and Moroccan immigrants in Belgium. Soc Psychiatry Psychiatr Epidemiol. 2008;44:188-97.

36. Ormel J, Wohlfarth T. How neuroticism, long-term difficulties, and life situation change influence psychological distress: a longitudinal model. J Pers Soc Psychol. 1991;60:744-55.

37. Saklofske DH, Kelly IW, Janzen BL. Neuroticism, depression, and depression proneness. Personal Individ Differ. 1995;18:27-31.

38. Slonim J, Kienhuis M, Di Benedetto M, Reece J. The relationships among self-care, dispositional mindfulness, and psychological distress in medical students. Med Educ Online. 2015;20:27924.

39. Brown KW, Ryan RM. The benefits of being present: mindfulness and its role in psychological well-being. J Pers Soc Psychol. 2003;84:822-48.

40. Bowlin SL, Baer RA. Relationships between mindfulness, self-control, and psychological functioning. Personal Individ Differ. 2012;52:411-5.

41. Weinstein N, Brown KW, Ryan RM. A multi-method examination of the effects of mindfulness on stress attribution, coping, and emotional wellbeing. J Res Personal. 2009;43:374-85.

42. Bränström R, Duncan LG, Moskowitz JT. The association between dispositional mindfulness, psychological well-being, and perceived health in a Swedish population-based sample: influence of dispositional mindfulness. Br J Health Psychol. 2011;16:300-16.

43. Derogatis $L R$, Melisaratos $N$. The brief symptom inventory: an introductory report. Psychol Med. 1983;13:595-605

44. de Beurs E. Brief symptom inventory Handleiding herziene editie 2011. Leiden: Pits publishers; 2011.

45. De Beurs E, Zitman F. De Brief Symptom Inventory (BSI). De betrouwbaarheid en validiteit van een handzaam alternatief voor de SCL-90. Leiden: Leids Universitair Medisch Centrum; 2005.

46. Ellis A. Reason and emotion in psychotherapy. Secaucus: Citadel Press; 1962.

47. Jones RG. A factored measure of Ellis' irrational belief system with personality and maladjustment correlates. Lubbock: Tex; 1968.

48. Shorkey $C T$, Whiteman VL. Development of the rational behavior inventory: initial validity and reliability. Educ Psychol Meas. 1977;37:527-34.

49. Timmerman I, Sanderman R, Koopmans P, Emmelkamp P. Het meten van irrationele cognities met de irrational beliefs inventory (IBI-50), een handleiding. Univ Med Cent Groningen. 2012; https://www.umcg.nl/ SiteCollectionDocuments/research/institutes/SHARE/assessment\%20tools/ handleiding_ibi2edruk.pdf. Accessed 31 Jul 2016

50. Koopmans P, Sanderman R, Timmerman I, Emmelkamp P. The irrational beliefs inventory (IBI): development and psychometric evaluation. Eur J Psychol Assess. 1994;10:15-27.

51. Baer RA. Using self-report assessment methods to explore facets of mindfulness. Assessment. 2006:13:27-45.

52. de Bruin El, Topper M, Muskens JGAM, Bogels SM, Kamphuis JH. Psychometric properties of the five facets mindfulness questionnaire (FFMQ) in a meditating and a non-meditating sample. Assessment. 2012;19:187-97.

53. Ross S, Cleland J, Macleod MJ. Stress, debt and undergraduate medical student performance. Med Educ. 2006;40:584-9.

54. Dyrbye LN, Thomas MR, Massie FS, Power DV, Eacker A, Harper W, et al. Burnout and suicidal ideation among US medical students. Ann Intern Med. 2008;149:334-41.

55. Borst JM, Frings-Dresen MHW, Sluiter JK. Prevalence and incidence of mental health problems among Dutch medical students and the studyrelated and personal risk factors: a longitudinal study. Int J Adolesc Med Health. 2016;28:349-55.
56. Bore M, Kelly B, Nair B. Potential predictors of psychological distress and well-being in medical students: a cross-sectional pilot study. Adv Med Educ Pract. 2016;7:125-35.

57. Chambers SK, Foley E, Clutton S, McDowall R, Occhipinti S, Berry M, et al. The role of mindfulness in distress and quality of life for men with advanced prostate cancer. Qual Life Res. 2016;25:3027-35.

58. Veehof MM, ten Klooster PM, Taal E, Westerhof GJ, Bohlmeijer ET. Psychometric properties of the Dutch five facet mindfulness questionnaire (FFMQ) in patients with fibromyalgia. Clin Rheumatol. 2011;30:1045-54.

59. Cash $M$, Whittingham $K$. What facets of mindfulness contribute to psychological well-being and depressive, anxious, and stress-related Symptomatology? Mindfulness. 2010;1:177-82.

60. Lamers SMA, Westerhof GJ, Kovács $V$, Bohlmeijer ET. Differentia relationships in the association of the big five personality traits with positive mental health and psychopathology. J Res Personal. 2012:46:517-24.

\section{Submit your next manuscript to BioMed Central and we will help you at every step:}

- We accept pre-submission inquiries

- Our selector tool helps you to find the most relevant journal

- We provide round the clock customer support

- Convenient online submission

- Thorough peer review

- Inclusion in PubMed and all major indexing services

- Maximum visibility for your research

Submit your manuscript at www.biomedcentral.com/submit 